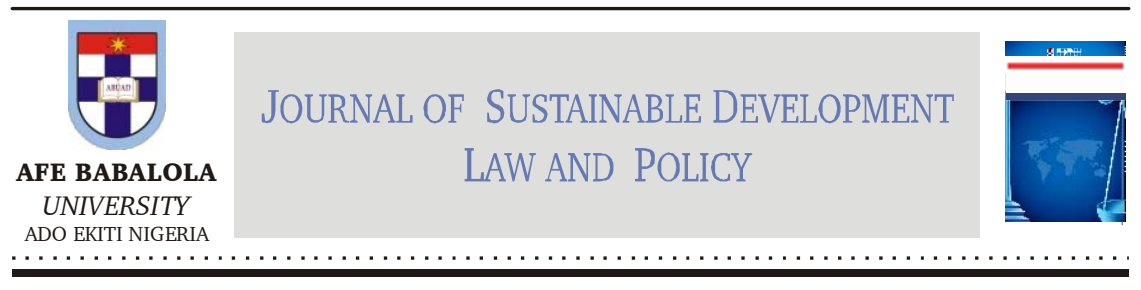

\title{
COMPARATIVE ANALYSIS OF GREEN BOND REGIMES IN NIGERIA AND CHINA
}

\begin{abstract}
Alex Oche*
ABSTRACT

Climate change has taken the centre stage in the debate of most governments around the world. At regional and international levels, efforts are being made to manage the problems emanating as a result of climate change. Response to the climate change can be summarized under two headings, namely, adaptation and mitigation measures. These measures do not come by cheaply, however. They are capital intensive; hence private sector funds will be needed to fund these adaptation and mitigation projects as public sector funding has remained insufficient. One way to mobilize private sector funds to tackle climate change is by using green bonds. But for green bonds to achieve its potentials as a sustainable investment tool, there must be a solid regulatory framework for the green bond market. Towards that end, this article analyses soft law instruments as well as national green bond regulations of Nigeria and China. It has been discovered that the Climate Bonds Standard and the Green Bond Principles form the basis of most jurisdictions of green bond regulations. nevertheless, due to regulatory arbitrage, there is no consensus green standard, and this poses a governance challenge to the green bond market. The article concludes that much of the responsibilities in setting green standards and enforcement of green standards rest on the domestic green bond regulations, and this can only be achieved with water-tight regulations for green bonds at domestic levels.
\end{abstract}

* Lecturer, College of Law, Afe Babalola University, Ado Ekiti, Nigeria. Associate Research Fellow, Institute for Oil, Gas, Energy, Environment and Sustainable Development. Email ocheaj@abuad.edu.ng 
Keywords: Climate Change; Green Bonds; Nigeria; China.

DOI: https://dx.doi.org/10.4314/jsdlp.v11i2.8

\section{INTRODUCTION}

With the overwhelming evidence of the impacts of global climate change and environmental hazards associated with hydrocarbon exploration and production on human life and survival, world leaders and economies alike have begun to make efforts to reduce reliance on fossil fuels while promoting economic growth. ${ }^{1}$ Climate change refers to any change in overall atmospheric weather over time, whether due to natural variability or as a result of human activity. ${ }^{2}$ The last nineteen years included eighteen of the warmest years on record, worsening food and water security risk, increasing the frequency and severity of hazards such as wildfires, landslides and floods. ${ }^{3}$ Huge amounts of fossil fuels have been burnt, and vast swathes of forests which could naturally absorb carbon dioxide - the main greenhouse gas responsible for global warming - have been cut down, thereby negatively affecting biodiversity and natural human habitat. ${ }^{4}$ Climate change affects natural human habitat and biodiversity in diverse ways; temperatures continue to rise, wildfires have become more frequent, tropical storms become more intense, sea levels may continue to rise, extreme droughts and flooding have become more common, causing displacement and conflict. ${ }^{5}$ Though climate change is

1 Damilola S. Olawuyi, The Principles of Nigerian Environmental Law (Revised edn, Afe Babalola University Press, 2015) 320.

2 Intergovernmental Panel on Climate Change Working Group II: Impacts, Adaptation and Vulnerability- Annex B: Glossary of Terms <www.ipcc.ch> accessed 28 September 2019.

3 New Climate Economy, "Unlocking the inclusive growth story of the 21st century: Accelerating climate action in urgent times" (2018 report) $12<$ https:// newclimateeconomy.report> accessed 28 September 2019.

4 Greenhouse gases are those gaseous constituents in the atmosphere, both natural and anthropogenic (generated by human activities), that absorb and emit radiation at specific wave lengths within the spectrum of infrared radiation emitted by the Earth's surface, the atmosphere and cloud. Examples of the most common greenhouse gases include, carbon dioxide, methane, perfluorocarbons, carbon monoxide, hydrofluorocarbons, nitrous oxide and sulfur hexafluoride. IPCC WGII Annex B: Glossary of Terms (n.2).

5 National Aeronautics and Space and Agency, "The Effects of Climate Change" <https://www.wwf.org.uk> accessed 10/10/18. Global Climate Change: Vital Signs of the Planet <https://climate.nasa.gov> accessed 10 October 2019. 
a global issue, its impacts are felt at local corridors, thus, it is imperative that governments at national levels device strategies to tackle climate change through adaptation and mitigation measures. How well societies respond to the climate change problems depend on the level of priority given to climate change related issues and the readiness to tackle such issues whenever they arise, using the readily available technologies and infrastructure. Globally, in 2017, disasters triggered by weather and climate-related hazards led to a staggering US $\$ 230$ billion loss. ${ }^{6}$ Between 2011 and 2017, communities in Nigeria have experienced severe droughts and flooding at alarming rates in all parts of the country, all owing to climate change impacts. ${ }^{7}$

The Intergovernmental Panel on Climate Change (IPCC), a scientific advisory body to the United Nations, released its first assessment report in 1990 which dealt with the science of climate change and its impact on human environment. Following the first assessment report countries around the world in 1992 joined an international treaty - the United Nations Framework Convention on Climate Change (UNFCCC) - as a framework for international cooperation, with the mandate to combat climate change by limiting average global temperature increases and coping with impacts of climate change. ${ }^{8}$ Since its first assessment report, The IPCC has released several other reports touching on the social and economic dimensions, adaptation and mitigation measures and policy options available to combat climate change. In its most recent report of October 2018, the IPCC made it clear that rapid, far reaching and unprecedented changes in all aspects of society must occur to ensure that temperature rises do not exceed 1.5 degrees Celsius above preindustrial levels, which if it does, would be catastrophic globally. More importantly, the report suggested that the financial system must be reshaped to accelerate investments in technologies, solutions and partnerships needed to decarbonize economies and promote behavioural

6 New Climate Economy (n.3).

7 See Nationally Determined Contribution (NDC) Implementation Department $<$ http://climatechange.gov.ng/nationally-determined-contribution-ndcimplementation/>; See also Nigeria's Intended Nationally Determined Contribution: Climate Change Impacts and Vulnerability <https:// Approved\%20Nigeria's\%20INDC_271115.pdf > accessed 31 October, 2019.

8 United Nations Framework Convention on Climate Change: History of the Convention <https://unfccc.int/process/the-convention/history-of-theconvention $>$ accessed 14 October, 2018. 
change. ${ }^{9}$ For climate change to be effectively managed, production and consumption patterns have to change, and financial systems have to be restructured in a manner that encourages investments in environmentally sustainable technologies (ESTs) and green initiatives.

The adoption and ratification of the Paris Agreement at the 21st Conference of Parties to the UNFCCC in 2015 reinforced commitments to tackle climate change. ${ }^{10}$ For the first time, countries all around the world came together and agreed on a single document that laid out a blueprint on how to tackle climate change through sustainable investment mechanisms. ${ }^{11}$ Primarily, the agreement set out to: keep global average temperatures well below 2 degrees Celsius above pre-industrial levels and to pursue efforts to limit the temperature increase to 1.5 degree Celsius above pre-industrial levels; increase the ability to adapt to the adverse impacts of climate change and foster climate resilience and reduce greenhouse gas (GHG) emissions in a manner that does not threaten food production; and make finance flows consistent with a pathway towards low GHG emission and climate-resilient development. ${ }^{12}$ Under the Paris Agreement, parties are required to make National Determined Contributions (NDCs) which will guide such countries in achieving individual emission reduction targets, with the collective aim of limiting global average temperature to below 2 degrees Celsius above pre-industrial

9 Environmental Finance, "No More Excuses: Financing 1.5C" < https:// www.environmental-finance.com/content/market-insight/no-more-excusesfinancing1.5c.html?utm_source $=121018$ na\&utm_medium $=$ email\&utm campaign=alert $>$ accessed 15 October, 2018.

10 This meeting was the 21st annual Conference of the Parties (COP) to the United Nations Framework Convention on Climate Change, held in Paris France, and the eleventh session of the parties to the Kyoto Protocol (1997). The Paris Agreement came into force on 30 November 2016 and sets out to reduce greenhouse gas emissions, mitigate and adapt climate change.

11 On 15 December 2015, the Paris Agreement on Climate Change was signed by 148 countries, the same year, the United Nations set Agenda 2030 for achieving new sustainable development goals, of which transitioning world economies from a carbon-based to a sustainable green economy is one of the key Agendas. These two major events acted as catalyst for sustainable investment globally; see SDG 13 <https://www.ng.undp.org/content/nigeria/en/home/ sustainable-development-goals/goal-13-climate-action.html $>$ accessed September 25, 2019.

12 United Nations, Paris Agreement COP 21 UNFCCC < https://unfccc.int/files/ meetings/paris_nov_2015/application/pdf/paris_agreement_english_.pdf $>$ accessed 25 September 2019. 
era. ${ }^{13}$ Having signed and ratified the Paris Agreement, ${ }^{14}$ Nigeria is bound under international law not to deviate from its obligation under the treaty, and to erect both legal and institutional frameworks to realise the obligation of the treaty. ${ }^{15}$

Nigeria's nationally determined contribution (NDCs) under the Paris Agreement is a 20 per cent carbon emission reduction by 2030 and a 45 per cent reduction with international support. ${ }^{16}$ This means that through domestic efforts to fund sustainable investment projects, Nigeria has committed to reduce carbon emission by 20 per cent, while with international support to reduce carbon emission by 45 per cent. Domestic efforts towards sustainable financing entails utilising sustainable investment tools like green bonds, (which is the focus of this article), equities or inclusion of green projects in the national budgets, while international support entails funding through international climate funds.

Global response to climate change can be summarised under two headings; mitigation and adaptation. ${ }^{17}$ However, these measures do not come cheaply. According to estimates by the International Energy Agency, about US\$ 9 trillion is required for the period 2016-2050 to decarbonize the power sector. Furthermore, to achieve the energy efficiency targets in the building, manufacturing, and transportation sectors, an additional

13 National determined contributions are commitments made by parties to the Paris Agreement in which states sets a specific target towards ecological conservations and reduction of greenhouse gas emissions.

14 Nigeria signed and ratified the Paris Agreement on 16 May 2016. See Paris Agreement- Status of Ratification < https://unfccc.int/process/the-parisagreement/status-of-ratification $>$; See also <https://treaties.un.org/pages/ viewDetails.aspx?src=TREATY\&mtdsg_noXXVII-7-d\&chapter $=27 \&$ clang $=$ en $>$ accessed 1 November 2019.

15 United Nations, Vienna Convention 1969 art. 26 which mandates parties to a treaty to take steps to perform their obligations under such a treaty in good faith, (pacta sunt sevanda-let the agreement be kept). See also, Malcom Shaw, International Law (6th Edn. Cambridge University Press New York, 2008) 903-4.

16 See Debt Management Office of Nigeria, Green Bonds Fact Sheet < https:// dmo.gov.ng/fgn-bonds/green-bond/2290-green-bond-factsheet/file > accessed 23 September 2019.

17 Climate change mitigation entails efforts aimed at reducing activities that cause climate change. For example, through utilising environmentally sustainable technologies that reduce anthropogenic emissions of GHGs into the atmosphere e.g. solar energy and low carbon electricity production. Adaptation on the other hand entails setting up infrastructures that are resilient to climate change 
investment of US\$ 3 trillion is required for 2016-2050. ${ }^{18}$ For Nigeria, about US\$ 142 billion is needed in green investment to meet the target set in its NDC under the Paris Agreement by 2030. ${ }^{19}$ Public funds alone will fall short in reaching these investment needs; hence private capital is also needed to cover the investment gap. One of the most promising mechanisms by which private sector capital can be mobilized in the fight against climate change is through the issuance of green bonds. ${ }^{20}$

Green bonds provide an opportunity for issuers to tap into international capital markets as well as domestic capital markets to mobilize private capital needed to cover the investment deficit needed to meet green economy needs. Aside that, green bonds generate earmarked funds for projects in renewable energy, energy efficiency, green buildings, restoring the environment to its pristine nature, and other eco-friendly projects, green bonds also tap the vast pool of financing held by institutional investors such as pension funds, insurance companies and sovereign wealth funds available in global capital markets. ${ }^{21}$ Also, issuing sovereign green bonds signifies government's efforts and commitments at national levels to transition towards a sustainable green economy. If utilized properly, green bonds have the potential to deliver low carbon and climate resilient infrastructure. However, to realize its full potentials as a veritable sustainable investment tool, a robust legal framework for green bonds must be put in place.

In search of key legal issues which are fundamental to a sustainable investment such as transparency, accountability, monitoring, definite green standards, safeguards against green washing - a major concern

impacts e.g. building sea walls, raising street levels, afforestation, investing in climate smart infrastructure like hurricane detection alarm systems among others See Damilola S. Olawuyi, "Advancing Innovations in Renewable Energy Technologies as Alternatives to Fossil Fuel Use in the Middle East: Trends, Limitations and Ways Forward" in Donald Zillman et al (eds), Innovation in Energy Law and Technology (Oxford University Press 2018) 360.

18 International Renewable Energy Agency, Perspectives for the Energy Transition: Investment Needs for a Low-Carbon Energy System (IEA Publications and IRENA Publications, March 2017) $8<$ www. Irena.org/publications/Mar/Perspectivefor-the-energy-transition-investment-needs-for-a-low-carbon-energy-system $>$ accessed 2 November 2018.

19 Federal Ministry of Environment, Green Bonds < https://www.environment. gov.ng > accessed 28 October 2019.

20 International Renewable Energy Agency, "Perspectives for the Energy Transition: Investment Needs for a Low-Carbon Energy System" (n 18).

21 International Finance Corporation, Green bonds <https://www.ifc.org > accessed 18 January 2019. 
for sceptics of green bond issuances ${ }^{22}$ - this article examines green bond private governance regimes, comprising voluntary process guidelines, and public regulatory regimes at national levels to assess their effectiveness in delivery of green promises via green bond issuances.

This article is divided into five sections, with the first being this introduction. Section 2 discusses the evolution of the green bond market and nature of green bonds. Section 3 analyses international green bond regulatory framework and the extent to which key legal and regulatory issues such as transparency on use of green bond proceeds, criteria for green project selection and eligibility, periodic reports and monitoring, and accountability, reflect in them. Drawing from the analysis made in the third section and in comparison with some select jurisdictions' green bond regimes, section 4 narrows down the discussion to Nigeria's green bond regulation in a bid to ascertain its parity with global best practices. Section 5 concludes the work.

\section{EVOLUTION AND NATURE OF GREEN BONDS MARKET}

\subsection{Evolution of the Green Bond Market}

The green bond market began with a climate awareness bond issued by the European Investment Bank (EIB) in 2007. ${ }^{23}$ From 2007-2012, the market mainly featured issuance of green bonds by Sovereign Supranational and Agency actors most notably the World Bank, along with a few local government funding agencies, municipalities and national development banks. With growing market appetite for such bonds there was increasing diversification of issuers and investors participating in the green bond market. Annual issuance of labelled "green bonds" rose from just US\$ 3 billion in 2012 to US\$ 47.8 billion in 2015 with issuance occurring in 14 of the G20 markets. Annual green bond issuance continues to grow rapidly and current estimates for 2016 range from US $\$ 72$ billion to US $\$ 100$ billion, with much of this growth being

22 Green washing is the deceptive promotion of the perception that an organisation's products, facilities or policies are environmentally friendly. Green washing is partly a function of lack of clarity regarding definitions, binding regulation and legal enforcement of the environmental credentials in most green bond markets.

23 International Finance Corporation, Green Bonds (n 21). 
the impact of Chinese issuers in the market. In the first seven months of 2016 , the amount of labelled green bonds issued by Chinese issuers (including domestic and overseas markets) reached US\$ 18.5 billion, accounting for about 42 per cent of global issuance during that same period. ${ }^{24}$ In the same year, Apple being the first technology company to access the green bonds market, issued green bonds worth US $\$ 1.5$ billion used in backing renewable energy for data centres, energy efficiency and eco-friendly materials. The seven-year security, with a coupon of 2.85 per cent, is the first green bond from the world's largest consumer electronics company and the largest single issue from a corporation unconnected to electricity generation.

Nigeria joined the green bonds market in December 2017, becoming the first African country to issue sovereign green bonds, and the world's fourth sovereign issuer of green bonds. The debut issuance was to the tune of N10.69 billion green bonds with a commitment to use the proceeds to finance green projects in the 2017 Appropriation Act. ${ }^{25}$ These projects included afforestation, renewable energy and the provision of clean energy to support education. The green bonds have a five-year tenor life cycle, and are guaranteed by the full faith and credit of the federal government, with a bi-annual interest payment. ${ }^{26}$ As at the time of issuance, there was no specific law for green bonds in the country; hence no endorsed domestic green bond standard. The Debt Management Office, which is the custodian of sovereign debts in Nigeria, adapted the ICMAs Green Bond Principles as its guidelines in utilization and management of the sovereign green bond proceeds. ${ }^{27}$ However, these guidelines applied only to the sovereign green bonds. The implication was that private sector issuances were to be left largely unregulated, giving chances for greenwash practices as experienced in the United States, ${ }^{28}$ and lack of transparency in utilization of green bond proceeds.

24 OECD, Green Bonds: Country Experiences, Barriers and Options (OECD 2016) <https://www.oecd.org/environment/cc/Green_Bonds_Country_ Experiences_Barriers_and_Options.pdf $>$ accessed 28 September $\overline{2} 018$.

25 Debt Management Office Nigeria (n 16).

26 Ibid.

27 Ibid.

28 Motoko Aizawa, "Reflections on the legal issues associated with green bonds" (Climate Bonds Initiative 2017) < https://www.climatebonds.net/2015/05/ reflection-legal-issues-associated-green-bonds-reflection-climate-bonds-seniorfellow > accessed 28 September 2019. 


\subsection{The Nature of Green Bonds}

A green bond is a debt instrument whose proceeds are used to finance environmentally friendly projects (green projects). They are called green bonds because proceeds from these bonds are used solely for financing green projects, which are basically climate change mitigation and adaptation projects. So far, this has been the underlying theme running through the majority of definitions of green bonds by renowned capital market experts and institutions. For instance, the International Capital Market Association (ICMA) defines a green bond as any type of bond instrument whose proceeds will be exclusively applied to finance or refinance in part or in full, new and/or existing eligible green projects. ${ }^{29}$ The Nigerian Stock Exchange defines a green bond as any type of bond instruments where the proceeds are exclusively used to finance or refinance, in part or in full, new and or existing eligible green projects that align with the four core components of the green bonds principles. ${ }^{30} \mathrm{~A}$ close look at the various definitions of green bond ${ }^{31}$ indicates that it possess a certain quality which differentiates them from a regular bond and qualifies them as green bonds. This quality being "the application of the bond proceeds to fund green projects". By adopting a literal interpretation of this qualifying character of the green bond, i.e. "use of proceeds to fund green projects", it will mean that a bond is green only if its proceeds are used to finance eco-friendly projects; hence fulfilling this special requirement becomes the determinant factor. ${ }^{32}$ The implication is that at the issuance stage the bond must demonstrate through its prospectus and legal documentation that indeed some eligible projects that will result in positive environmental impacts will be funded with

29 nternational Capital Markets Association (ICMA), "The Green Bond Principles" (June 2018) <www.icmagroup.org > accessed 22 February 2019.

30 Nigerian Stock Exchange Green bonds < https://www.nse.gov.ng/> accessed 15 December 2018.

31 Ernst \& Young LLP, "Green bonds: a fresh look at financing green projects" 3 $<$ Documents/EY-Green\%20bonds-a-fresh-look-at-financing-green-projects.pdf $>$ accessed 15 December 2018; See also Debt Management office of Nigeria (DMO), "The Debut Federal Government of Nigeria Green Bonds" < http:// www.dmo.gov.ng/fgn-bonds/green-bond/Downloads/Green\%20Bond\%20 Factsheet.pdf $>$ accessed 15 December 2018.

32 Annica Cochu et al, "study on the potential of green bond finance for resourceefficient investments" (European Commission, 2016) < http://ec.europa.eu/ environment/enveco/pdf/potential-green-bond.pdf $>$ accessed 26 January 2019. 
the bond proceeds. ${ }^{33}$ Fulfilling this criterion, i.e., use of proceeds becomes a prerequisite for a bond to assume the "green standard", it forms the basis for qualifying a bond as green. ${ }^{34}$ Consequently, for a bond to maintain its green quality, it must abide by its green promises and follow through on it throughout the life cycle of the green bond to avoid legal or reputational risks that may follow. ${ }^{35}$ Tracking the bond proceeds, management and monitoring of proceeds, periodic reports on project impacts throughout the life cycle of the bond becomes necessary to ensure the bond stays green. ${ }^{36}$ Anything short of this robs the bond of its "green standard" and not even the mere presence of a "green label" can alter this. ${ }^{37}$ However, the consequence of a shift from the green standard depends on the regulation guiding issuance of the bond.

Although there seems to be a consensus on the definition of green bonds, what is not clear is the delimitation of what amounts to a green project. Widely accepted guiding documents like the Green Bond Principles $^{38}$ and the Climate Bonds Standard ${ }^{39}$ each contain a list of eligible green projects, but they do not delimit what should not be classified as a green project. This situation is also present in the green bond regulation of some countries, a typical example being Nigeria's green bond rules, ${ }^{40}$ and the Guidelines for issuing green bonds in Brazil, endorsed by the Brazilian Federation of Banks (FEBRABAN) and the Brazilian Business Council for Sustainable Development (CEBDS) which contains a list of what may classify as green projects. Some scholars see this as an advantage, arguing that the situation gives room for including innovative technologies in the green project list as technologies advance. ${ }^{41}$

33 See generally ICMA, The Green Bond Principles (n 29).

34 Ibid.

35 Aaron Franklin, "How to minimise legal risk of green bond" (Environmental Finance (May 2017), < https://www.environmental-finance.com/content/ analysis/how-to-minimise-the-legal-r.pdf $>$ accessed 22 February 2019.

36 See generally ICMA, Green Bond Principles 2018 (n 29); Climate Bonds Initiative, Climate Bonds Standard (2018).

37 Aaron Franklin, (n 35).

38 ICMA, The Green Bond Principles (n 29).

39 Climate Bond Initiative, Climate Bonds Standard version $2.0<$ https:// www.climatebonds.net/standards_pdf> accessed 23 February 2019.

40 Green Bond Rules 2018.

41 Christa Clapp, What Is Green and the Developing Green Standard (CICERO 2018) <https://www.environmental-finance.com/content/the-green-bond-hub/ what-is-green-and-the-developing-green-standards.html> accessed January 18, 2019. 
On the other hand, it is possible that the term green may become relative, with various issuers deciding various taxonomies of green projects according to their economic priorities and preferences. The implication is that hydro-carbon intensive projects may still be funded by finances sourced from the green investment pool. ${ }^{42}$ This situation presents a governance challenge which has become heightened due to the absence of a consensus green bond standard caused by regulatory arbitrage, as currently the green bond market is largely regulated by multiple private governance regimes which allow for the selection of regulatory frameworks most suitable to their interests. ${ }^{43}$

\section{ANALYSIS OF INTERNATIONAL GREEN BOND REGULATORY FRAMEWORK}

Owing to its trans-boundary nature, and the fact that sustainable finance was first propelled by international institutions, the green bond market is largely regulated by private governance regimes comprising quasiregulatory standards, procedures and institutions which lack coercive authority of government. Rather, their standards rely on market-based signals to regulate through peer pressure, reputational leverage and other market-based mechanisms. ${ }^{44}$ The analysis in this section is limited to the green bond principles and the climate bonds standard. The Green Bonds Principles (GBP) and the Climate Bonds Standard are the two most popular international guidelines for issuing green bonds and they form the basis of most jurisdictions' green bonds regulation. ${ }^{45}$

\subsection{The Green Bond Principles}

The Green Bond Principles (GBP) was launched in 2014 by the

42 Shuang Liu, Will China Finally Block Clean Coal from the Green Bonds Market? $<$ https://www.greenbiz.com/article/will-china-finally-block-clean-coal-greenbonds-market $>$ accessed 19 August 2020.

43 Stephen Kim Park, "Investigators as regulators: green bonds and the governance challenges of the sustainable finance revolution" [2018] SJIL 1, 31.

44 Ibid.

45 The GBP has achieved broad market acceptance and legitimacy, as well as growing official recognition by policy makers and regulators. As at June 2017, 135 green bond issuers, underwriters and investors have become members of the GBP and in excess of 110 organisations are observers; See also SEB, "Green Bonds- Ecosystem, Issuance Process and Case Studies" <www.seb.se/ greenbonds /giz_seb_greenbondpublication_web.pdf > accessed 4 March 2019. 
International Capital Market Association (ICMA) and has continued to undergo yearly review to reflect recent developments and growth in the green bond market. The GBP are voluntary process guidelines for issuing green bonds intended for use by capital market participants desirous of using fixed debt securities to invest in environmental sustainability through specific projects. ${ }^{46}$ The ICMA acts as Secretary to the GBP advising on governance and other matters, as well as providing organizational support. The principles are centred on four key components which seek to ensure transparency, accountability and sustainability in using green bonds. These components include use of proceeds; evaluation and selection; management of proceeds; and reporting.

\subsubsection{Use of Proceeds}

The use of proceeds component require that proceeds of the bond should be used for identified green projects, which should be appropriately described in the bond prospectus and application documents for approval of the bond. ${ }^{47}$ All designated green projects should provide clear environmental benefits which should be assessed and, where feasible, quantified by the issuer. Such projects include renewable energy, energy efficiency, pollution prevention and control, clean transportation, sustainable water management, terrestrial and aquatic biodiversity conservation, climate change adaptation projects, green buildings and eco-efficient products. However, the list of green projects contained in the GBP is not delimited nor does it exclude projects which ordinarily should not be classified as green due to their carbon intensive nature. This situation leaves room for diverting green bond proceeds to carbon intensive projects, for instance, the Peoples Bank of China $(\mathrm{PBoC})$ green bond regulation includes coal development in its list of eligible green project. This problem is further compounded where there is no definite green standard across board.

\subsubsection{Project Evaluation and Selection}

This component mandates issuers to outline environmental sustainability objectives of the bond in the legal documentation, the process by which the issuer determines how projects are selected, and how they will achieve

46 ICMA - "The Green Bond Principles" (n 29).

47 ICMA, The Green Bond Principles (use of proceeds section). 
those environmental sustainability objectives of the project. For example, if a green building project is listed in the prospectus to be funded by proceeds from the green bond, the issuer is expected to disclose LEED certification details. ${ }^{48}$ The project evaluation and selection criteria becomes very important as it casts a search light on project selection process and ensures that the projects are not mere lofty expectations, but will indeed have feasible eco-friendly impacts.

\subsubsection{The Management of Proceeds}

This component requires that funds realized from green bonds are not mixed with those from other sources in order to ascertain the real value of an issue, as well as track the proceeds. It requires that proceeds from the bonds be credited to a sub-account and tracked by the issuer to reflect the issuers lending and investment operations for green projects. ${ }^{49}$ The essence is to disclose the formal internal process of how the issuer intends to disburse funds for the nominated green project. Where the funds are currently unallocated, the issuer should disclose the intended type of temporary placements for unallocated proceeds. ${ }^{50}$ The reason for this is obvious - so that investors can monitor and influence the use of their funds at almost every given time.

\subsubsection{Reporting}

The reporting component is most crucial to a green bond's life-cycle. It ensures transparency and monitoring which is very crucial to integrity of the green bond market. The component requires that an issuer makes and keeps readily available up-to-date information on the use of proceeds from the bond. The report should include a list of the projects to which the proceeds of the bond have been allocated, as well as the amounts allocated, expected, and achieved impacts of the green projects. As regards impact of the green projects, the reporting component requires the use of qualitative performance indicators and quantitative performance measures

48 "LEED" acronym for "Leadership in Energy and Environmental Design" was established by the US Green Building Council in response to a perceived need that specific and determined standards and third-party verification by required in order for structures to be considered environmentally friendly; See Damilola Olawuyi, Principles of Nigerian Environmental Law (Afe Babalola University Press 2015) 317.

49 ICMA Green Bond Principles (management of proceeds section).

50 Ibid. 
(e.g., energy capacity, electricity generation, greenhouse gas emissions reduced/avoided, number of people provided with access to clean power, decrease in water use, reduction in the number of cars required, among others.), for disclosing information contained in the report. ${ }^{51}$ However where competition or confidentiality will be affected the GBP recommends presentation of information in generic terms.

In order to safeguard its tenets, the GBP recommends second opinion reviews to be conducted by institutions with environmental expertise independent of the issuer. External reviews are conducted to ensure alignment with the core components of the GBP. External reviews can be done via second party opinion providers such as Cicero, ${ }^{52}$ Certification, or Green ratings by green bonds rating agencies who focuses on the environmental performance of the bonds and not just on their creditworthiness.

As robust as the GBP principle may seem, it still suffers some limitations which may hinder its relevance as a model green bond regulation. The GBP recommends verification of the green bond framework by external reviewers at the pre-issuance stage, however, it does not make post issuance reports on impacts of green project by external reviewers mandatory, neither does it set standards for external reviewers. Making post-issuance report verification mandatory will serve as check to ensure that an issuer follows through on the green promises of identified green projects. Also, the GBP has no monitoring mechanism to ensure compliance with its provisions. Unlike its contemporary, the Climate Bond Standard Certification Scheme (CBS), ${ }^{53}$ which uses a certification scheme where a board approves verifiers and issues certificates and labels set against CBS standards, the GBP leaves it to an issuer to decide whether or not to follow its recommendations, without any hints as to consequence of not.

\subsection{The Climate Bond Standard Certification Scheme}

The Climate Bonds Standard Certification Scheme (CBS) operates a closely

51 ICMA Green Bond Principles (reporting section).

52 Cicero Shades of Green provides independent research-based evaluations of green bond investment frameworks to determine their environmental robustness. For further readings, See Cicero, "Shades of Green" < https:// www.cicero.green/> accessed 4 March 2019.

53 Climate Bond Initiative, Climate Bonds Standard $2.0<$ https:// www.climatebonds.net/standards_pdf $>$ accessed 4 March 2019. 
guarded certification scheme for green bond issuances. The CBS includes robust framework for monitoring, reporting and assurance of conformity with the climate bonds standard which is built around a scientific framework that defines which projects or assets are consistent with a low carbon and climate resilient economy. An alignment of a bond issue with the CBS automatically aligns the bond issuance to the $\mathrm{GBP},{ }^{54}$ however, the CBS goes a step further by requiring specific eligibility criteria for low carbon and climate resilient projects chosen by an issuer. ${ }^{55}$ The certification process comprises pre-issuance requirements, post-issuance requirements and a suit of sector-specific eligibility and guidance documents. The Certification Scheme is overseen by the Climate Standard Board; a board of independent members comprised of institutional investors, leading environmental NGOs and scientists who approve the standard, sectorspecific criteria, verifiers, and make decisions on certification of a bond. ${ }^{56}$ Furthermore, the CBS certification scheme goes beyond recommending broad integrity principles as in the case of the GBP, but creates a robust and effective certification system where issuers have to conform to certain criteria listed in the CBS at pre-issuance stage in order to obtain a certification mark, and post-issuance requirements to retain the certification mark after issuance of the bond. ${ }^{57}$

To ensure that issuers follow through on the green promises of selected green projects, the CBS mandates an issuer to complete an "assurance engagement" and submit the verifier's report to the CBS Board to maintain the certification mark of the bond awarded at the pre-issuance stage, proving its conformity with the Board's Standard. This post-issuance "assurance engagement" must be completed within one year of the bond's issuance. Where the Board is satisfied that the Issuer and the bond are compliant with the post-Issuance requirements of the CBS, then it shall provide a statement that confirms the certification of the bond. The Issuer then has the right to continue using the Climate Bond Certification Mark in association with the relevant bond (but not others) for the duration of the bond term. However, the Board reserves the power to revoke the certification mark where it discovers that the bond is no longer in conformity with the CBS standard. Where the certification

54 Climate Bonds Initiative, Climate Bonds Standard 2.1 part A (Climate Bond Initiative 2018).

55 Ibid.

56 Ibid.

57 Ibid. 
mark is revoked, the issuer is required to inform the bondholders, the relevant exchanges and the climate bond market participants of the change in the certification status of the bond.

It is indicative that through issuance and revocation of certification marks, the CBS certification scheme seeks to tighten enforcement of its standards, however, the CBS enforcement mechanism seems to have loopholes which an issuer could manipulate to its advantage. For instance, the CBS is silent on the implication of continuous usage of the certification mark even where it has been revoked by the board. Lax enforcement mechanism happens to be a common feature of private governance regimes; hence enforcement may be achieved at national levels through legislative and institutional regulations.

\section{COMPARATIVE ANALYSIS OF GREEN BOND REGULATIONS IN NIGERIA AND CHINA}

This section compares the green bond regulatory regime of China with that of Nigeria. Although the legal systems of both countries differ, with China's legal system based on civil law and that of Nigeria based on common law, both countries share similarities of being major contributors to global warming. Majority of China's electricity is generated from coal, ${ }^{58}$ China is also the world largest petroleum importer. Nigeria, on the other hand, is largely dependent on crude oil for export revenue, power generation and has a notorious reputation of gas flaring practices. However, China is a major front runner in the green bond market, with more elaborate green bond regulations and guidelines. ${ }^{59}$ China also has the world's largest green bond market, accounting for about 39 per cent of global issuances. ${ }^{60}$ Therefore, this places it in a better position as a

58 Jing Xuan Teng, "China Adds Coal Power Despite Climate Pledge: Report" <https://phys.org/news/2019-11-china-coal-power-climate-pledge.html> accessed 22 December 2019.

59 Echo Xaixi Wang, "Financing Green: Reforming Green Bond Regulation in the United States" (2016) (12) (2) Brooklyn Journal of Corporate, Financial and Commercial Law. 478; See also Climate Bond Initiative, "Myth buster: why China's green bond market is more orderly than you might think. An Overview from Climate Bonds Initiative" < https://www.climatebonds.net/2017/06/ myth-buster-why-china $\%$ E2\%80\%99s-green-bond-market-more-orderly-youmight-think-overview-climate > accessed 19 March 2019.

60 Paul Davies, Aaron Franklin and Andrew Westgate "China's Securities Regulator Issues New Green Bond Guidelines" (5 April 2017) <www.latham.london> accessed 19 March 2019. 
comparator country with Nigeria who is still new to green bonds practice. Lessons drawn from China's implementation of the green bond regime could help Nigeria understand the key opportunities, requirements and challenges associated with green bond regulation.

\subsection{Nigeria}

The Investments and Securities Act (ISA) 2007 is the principal legislation governing securities transactions in Nigeria. The Act establishes the Securities and Exchange Commission (SEC), ${ }^{61}$ which serves as the apex regulator of the Nigerian capital market. ${ }^{62}$ The SEC is empowered under section 313 of the ISA to make rules and regulations to effectuate the provisions of the ISA and also generally for capital market operations in Nigeria. To that effect, the commission, recently released the Green Bond Rules 2018 (the Rules) to regulate issuance of green bonds in Nigeria. Under the Rules, a state government, local government, corporation or supranational agency can issue a green bond. ${ }^{63}$

On qualification, in order for a green bond to be approved, the Rules require that in addition to the general requirements for debt issuances stated in the regulations of the commission, ${ }^{64}$ an issuer is to file a "letter of commitment" with the Commission, committing to invest all the proceeds of the bonds in those projects that qualify as green projects in accordance with the rules; a feasibility study report stating the benefits of the green projects; a prospectus which include project categories, project selection criteria, decision-making procedures, environmental benefits, use and management of the proceeds; an independent assessment or certification issued by a professional certification authority or person approved or recognized by the Commission.

The Rules contain a list of projects that qualify as a green project, they include renewable and sustainable energy, clean transportation, sustainable water management, climate change adaptation, energy

61 Investment and Securities Act 2007, s 1.

62 ISA 2007, s 13.

63 Green Bond Rules 2018, r 3.0.

64 Those conditions include filing a registration statement, general company documents and resolution as required by SEC, together with a prospectus with mandatory contents. With the Green Bond Rules stating the mandatory contents for the prospectus of a green bond, those will apply instead of the mandatory contents as stated in the consolidated rules. See SEC Consolidated Rules 2013, r 567; See also Green Bond Rules 2018, r 3.0 (iii). 
efficiency, sustainable waste management, sustainable land use, biodiversity conservation, and green buildings. ${ }^{65}$ Also, while, the list of eligible green projects contained in the Rules does not include fossil fuel projects as one of those projects which green bonds proceeds could be funded with, it does not explicitly exclude fossil fuel projects, rather, the list indicates an unending character as it ends with the wordings "and any other project the Commission may approve" 66 This situation may present an avenue for funding non-green projects with green bond proceeds and has been considered worth addressing in some jurisdictions. For example, the Philippines Green Bond Rules 2018 maintains an outright ban on fossil fuel power generation projects from those projects which green bond proceeds could be funded with.

According to rule 4.0 (i) of the Rules, proceeds of the bonds can be used for only those purposes stated in the approved offer documents, which are limited to those eligible green projects approved by the rules as stated above. On the management of proceeds, the Rules mandate that a separate account is maintained for the net proceeds of the offer from which projects are to be funded. However, regarding the process of project evaluation and selection, the Rules are silent on requirements of what the process should entail or what standards should be met.

On reporting, which is very crucial to the success or failure of green bonds and green projects monitoring, the Rules provide that the issuer is to provide a green bond report to the commission annually. The report is to state the project to which proceeds from the bonds were applied, the amounts disbursed, expected impact of the projects, qualitative and quantitative performance indicators, and the methodology used to prepare those indicators. Further, the Rules require that the issuer is to publish an assessment report of the green project and its associated benefits. This report is to be conducted by an independent professional assessment agency and to be published annually. However, like its progenitor the GBP, verification of post-issuance assessment report is not mandatory under the Rules, nor does it state the implication of publishing an inadequate assessment report.

\subsection{China}

Although China's Green bond regulatory regime is not codified in one

65 The eligible green projects as listed in the rules are in pari materia with those listed in the green bond principles. See Green Bond Rules 2018, r 2.

Ibid. 
law, an overall view of the subsisting regulations reveals that green bond regulations in China are stricter in ensuring compulsory pre- and postissuance standards compliance when compared to Nigeria.

Green bonds regulation in China is primarily divided on the basis of the type of issuer. The Peoples Bank of China (PBOC) regulates issuances from financial institutions using the Peoples Bank of China Executive order 39 (2015). The National Development and Reform Commission (NDRC) regulates issuances by corporations without listed equity, using NDRC Executive order 3504 (2016). The China Securities Regulatory Commission (CSRC) regulates all issuances by listed companies using the Securities Regulatory Commission Green Bond Guideline (2017).

Chinese issuers are required to make periodic quarterly reports on the performance of the bond and the green projects, which are to be reviewed at every instance by an external reviewer. ${ }^{67}$ The Green Bond Assessment and Verification Guidelines (Provisional) 2017 provides for a Green Bond Standard Committee whose functions include approving verifiers and certification agencies, reviewing external verifiers' reports, penalizing defaulters, revoking green labels, and so on. ${ }^{68}$ Though issuers are regulated by separate bodies according to the type of issuer, by virtue of the Green Bond Assessment and Verification Guidelines (Provisional) 2017, the Green Bond Standard Committee acts as supervisory regulator over all green bond regulatory bodies.

Before verifiers can undertake green bond reviews, they will have to register with the green bonds standard committee and provide evidence of professional expertise in assurance, accounting and auditing, and expertise in key qualifying sectors such as clean energy and lowemission. ${ }^{69}$ Also, verifiers are mandated to make both pre-issuance and post-issuance reports, and to also gauge whether the expected environmental impacts of green projects are reasonable or not. ${ }^{70}$ The Guidelines also set standards for verification reports by setting requirements on what should be reported and how. They include information of the green bond; environmental impact of green projects;

67 Peoples Bank of China Executive Order No.39 2015, art 5. See also China Securities Regulatory Commission Guidelines 2017, art 4.

68 Green Bond Assessment and Verification Guidelines (Provisional) 2017, art 2. <http://www.pbc.gov.cn/goutongjiaoliu/113456/113469/3449947/ index.html > accessed 23 December 2019.

69 Green Bond Assessment and Verification Guidelines (Provisional) 2017, art 3.

70 Ibid art 4. 
detailed description of the verification methods; and a summary report. ${ }^{71}$ The verifiers' assessment report is then submitted to the Green Bond Standard Committee.

Whenever a verifier submits a post-issuance report with a negative conclusion regarding the green bond obligation and promises, and the bond issuer fails to comply with the relevant standard even after the rectification period, the green label will be revoked for the remaining time of maturity and recertification is not allowed. ${ }^{72}$ The implication of this is that the bond loses its green status and an investor may exercise "a put option". ${ }^{73}$

Verifiers are mandated to conduct their reviews with truthfulness and fairness at all times. In the event of submission of false information, or breach of professional ethics and independence requirements in conducting reviews, verifiers shall be penalized by fine, and/or suspension from further verifying any green bond for a given period according to the green bond standard committee's discretion.

In accordance with the Green Bond Project Catalogue endorsed by the Chinese government, green projects are classified according to China's national development plan. Unlike the green project taxonomy of other jurisdictions - for example, Nigeria and Brazil - the classifications of green projects are more detailed and based on scientific criteria and national environmental development plans. This makes it a lot easier to disclose the "process of project evaluation and selection" as required by international best practice standards, ${ }^{74}$ and more practicable in realizing green project impacts. Furthermore, having scientific basis for classifying green projects gives the definition of green bonds in China a substantive basis, thereby reducing the probability of green washing practices. However, contrary to international standards where fossil fuel projects are excluded from eligible green projects, ${ }^{75}$ China's green bond catalogue contains clean coal development as one of those projects that green

71 Ibid.

72 Green Bond Assessment and Verification Guidelines (provisional) 2017, art 5.

73 A put option compels the issuer to buy back the bond when a green label is revoked.

74 ICMA, Green Bonds Principles 2018 (n 29); CBI, Climate Bonds Standard 2018 (n 39).

75 Kelly Yu, Green Bonds, "Green Boundaries: Building China's green financial system on a solid foundation" (International Institute for Sustainable Development 2016) < https://www.iisd.org/blog/green-bonds-greenboundaries $>$ accessed 19 March 2019. 
bond proceeds can be applied towards. This may be due to the fact that China produces more than half of its electricity from coal, thus reflecting the different priorities and needs of emerging and developed countries in defining their green investments.

\subsection{Barriers to Efficient Green Bond Regulation in Nigeria: Lessons from China}

The comparative analysis conducted above has highlighted certain aspects of Nigeria's green bond regulation that can be improved upon. These barriers are dis used next with a view to proffering solutions them.

\subsubsection{Inadequate Reporting and Verification Standards}

As mentioned earlier, reporting is a very crucial aspect of green bonds as it ensures transparency and effective monitoring of the use of proceeds, which is very critical to the integrity of the green bond market. Reporting also helps in ascertaining the impacts of green projects. Reporting is a required component of green bond practice globally. ${ }^{76}$ As a form of check, verification of green bond reports are conducted by independent external reviewers using an assessment report in order to ensure its credibility. Nigeria's Green Bond Rules (2018) provides for preparation and filing of annual green bond reports, as well as the need for an assessment report by an independent assessor. However, the Rules are silent on the need for verification of these assessment reports. This is because the Rules also do not provide for any standards that should be met by an assessment report, or on whether the assessment reports should be verified by SEC. ${ }^{77}$ Although a case of false or inadequate assessment report is yet to occur, the absence of verification standards in the Rules points out a gap that needs to be filled to prevent such incidences from occurring. In China, external verification assessment reports are required to meet standards set by the Green Bond Standard Committee. These standards include items such as information of the green bond; environmental impact of green projects; detailed description of the verification methods for assessing impacts; and a summary report. Setting standards for external assessment reports is important for testing the credibility of green bonds and for verifying the impact of green projects. It ensures that verification

76 ICMA, Green Bond Principles: reporting section (n 29); CBI, Climate Bond Standards 2018 (n 39).

77 Green Bond Rules 2018, r 5.0 (ii). 
is conducted in a more orderly and prudent manner, as well as forecloses the likelihood of inconsistent forms of assessment reports which may be induced by the pecuniary interest on the part of external assessors on the one hand or the mere need to meet bureaucratic requirements on the par, on the other hand. Examples could be taken from China by including standards which assessment reports in Nigeria's Green Bond Rules must meet. This will reduce chances of green washing and other sharp practices. Such standards could include sector-specific requirements for qualification as a verifier, methods of assessing project impacts, and internal process assessment.

\subsubsection{Inadequate Enforcement Mechanism}

The green bond process involves several stakeholders and actors, such as issuers, investors, external reviewers, market regulators who all play several roles, but with the collective goal of ensuring that green bond proceeds eventually realize positive environmental impacts. At domestic levels, government regulators play the critical role of monitoring and supervision. They approve eligible green projects, set green label standards, verify and approve progress reports, met penalties where there are defaults, exercise quasi-judicial functions, among a host of other things. ${ }^{78}$ These functions can only be exercised properly if regulation is backed by legal authority, but this is not the case in Nigeria. The Green Bond Rules 2018 is silent on consequences of not complying with green promises, or on publishing inadequate or false green bond reports. This creates a loophole and incapacitates regulators from enforcing green standards especially for post-issuance requirement compliance, as the Rules do not provide any penalty for default of any of its mandates. The closest provisions enabling SEC as a regulator to penalize default in fulfilling bond obligations is rule 566 (f) of the SEC Consolidated Rules 2013 which provides for payment of principal and interest within three months in case of default. For green bonds, a default in any of the green obligations or promises in the bond prospectus should ordinarily attract liability since they form the criteria for classifying a bond as green. However, the Consolidated Rule is not clear on whether "default" here covers default on any obligation of a bond at all, or only default related to payment of principal sum or interest. If this is the case, then it does little to address potential breach on green bond promises or other green bond regulation

78 See section 2 above "nature of green bond". 
requirements. In comparison to China's green bond regulation, whenever a verification assessment report reveals a negative conclusion, and an issuer fails to rectify the anomaly during the rectification period, the green bond certification is revoked by the green bond standard committee and an investor is allowed to exercise a put option. ${ }^{79}$ This revocation mechanism keeps issuers on their toes, as revoking a green bond certificate will mean reputational loss and liability for a green bond issuer. This penalty mechanism present in China's green bond regulation ensures compliance with pre- and post-issuance requirements of the green bond. Nigeria's Green Bond Rules can be amended to include penalties for breaching provisions of the rules. This will go a long way in ensuring that issuers meet their green promises, as well as increase investor confidence in Nigeria's green bond market.

\subsubsection{Lack of Substantive Criteria for Classifying Green Projects}

Green projects are the central focus of green bonds issuers, as utilizing proceeds of the bonds on projects that result in environmentally friendly outcomes is the basis for classifying a bond as green. In identification and selection of green projects, it is important that they are realistic with their sustainability aspirations and in deed capable of resulting in feasible positive environmental impacts. The list of eligible green project, as listed in international green bond guidelines such as the Green Bond Principles (GBP) or the Climate Bonds Standard, is more of an indicative list meant to guide jurisdictions in formulating their own list of green projects. ${ }^{80}$ Most jurisdictions have adapted the list of green projects as contained in those guidelines as their green project taxonomies. For example, the list of green projects in Nigeria's Green Bond Rules 2018 (the Rules) are in pari materia with that of the GBP. While this is an applaudable gesture, one cannot help but wonder how those projects reflect the peculiar climate change related problems of the various countries and how they proffer solutions to these problems. Working with a national development plan and sector-specific standards in

79 Green Bond Assessment and Verification Guidelines (provisional) 2017, art 5.

80 The GBP provide an indicative category of eligible Green Projects in recognition of the diversity of current views and of the ongoing development in the understanding of environmental issues and consequences, while liaising when needed with other parties that provide complementary definitions, standards and taxonomies for determining the environmental sustainability of projects. 
developing a list of eligible green projects is a good starting point in arriving at a substantive basis for identifying projects. Doing so will ensure that priority sectors are impacted; a pipeline of eligible green projects for the green bond market is available; also a standard for gauging potential and achieved impacts of green projects are provided. For example, for a green project like constructing a high efficiency facility intended to contribute to energy saving, the defining criteria will be set against the national standard of energy consumption allowance for unit product, but this is only possible where such standards exist. However, this is not the case with Nigeria, as the list of green projects in the Rules are bland without any definitive criteria. Nigeria is yet to have national a standard for energy consumption, and this is due to poor metering of grid electricity and also because most buildings generate their electricity using petrol or diesel powered generators. ${ }^{81}$ Circumstances like this make it difficult to back the list of green projects in the Rules with any form of definitive substantive criteria. Ideas can be taken from the People's Bank of China Green Endorsed Project Catalogue, where the list of green projects are accompanied with substantive definitive criteria standing on their national development plan and sector specific standards. ${ }^{82}$ Having substantive criteria for classifying green projects for Nigeria will entail having a sustainable development inclined national master plan that maps out sector-specific standards, which green projects could be built upon.

\subsubsection{The Problem of Locating Green Projects}

The Rules are silent on where green projects should be located. It may not be out of place to consider situations where proceeds from a bond issue could be used in carrying out green projects outside Nigeria, thereby depriving its citizens of the direct benefits of such green projects, since there is no law prohibiting an issuer from exporting proceeds of a bond issued. This circumstance has been considered and, in some jurisdictions, laws have been made that ensure green projects are erected where the

81 Federal Ministry of Power Works and Housing, Building Energy Efficiency Guideline for Nigeria (June 2016) < https://energypedia.info/images/c/c7/ Building_Energy_Efficiency_Guideline_for_Nigeria_2016.pdf $>$ accessed 19 March 2020.

82 China Green Bond Endorsed Project Catalogue (2015) < http://www. greenfinance.org.cn/displaynews.php?cid=79\&id=468 $>$ accessed 19 March 2020 . 
bonds were issued. For example, the Philippines Guidelines for Issuance of Green Bonds 2018 provide that proceeds from green bonds must be invested in green projects situated in the Philippines or any of the ASEAN countries. It is recommended that the SEC Green Bond Rules 2018 be amended to ensure that proceeds from green bonds issued in Nigeria are channelled towards projects that must be situated in Nigeria.

\section{CONCLUSION}

The green bond market is still new to Nigeria and most parts of the world. Green bonds have the potential of mobilizing private sector capital needed for investing in climate change mitigation and adaptation projects. However, this potential is largely dependent on the existence of a robust regulatory framework that addresses such issues. Among the issues to be covered under this framework are green standards definition; criteria for selecting green projects; periodic progress reports on impacts of green projects; enforcement mechanisms; transparency, and accountability. All of these are critical to a sustainable green bond market.

Nigeria's green bond green regulatory regime has been examined and comparatively analysed with the Chinese green bond regulations. While Nigeria can be applauded for being one of the first countries globally to engage in the green bond market, the analysis reveals that much still has to be done in terms of regulations, as some lacunae exist in the present green bond regulation that must be addressed for a sustainable green bond market devoid of greenwashing to emerge. First, is the absence of verification requirement for project assessment reports. This presents an avenue for cases of inadequate or false green project impact assessment reports. Connected to this is lack of substantive criteria for defining green projects. This problem frustrates efforts to monitor or gauge the real impact of green projects, since the list of green projects in the current SEC Green Bond Rules appear to have been copied from the GBP without being tailored to meet domestic sector specific standards. Lastly is the absence of penalties in the Green Bond Rules where there is breach of any of its provisions. This undermines the capacity of SEC to enforce green standards. If the rules can be amended to address these highlighted issues by adopting the recommendations made in this article, Nigeria will have a better green bond regulation that guarantees green promises and be placed in a better position of transitioning to a green economy. 